\title{
Research on the Development of Number of Postgraduate Students on Campus in China
}

\author{
Xiaoshu Wang ${ }^{\mathrm{a},{ }^{*}}$, Le Wang ${ }^{\mathrm{b}}$ and Wanliang Dai $^{\mathrm{c}}$ \\ Bohai University, Jinzhou, Liaoning, China \\ a49718990@qq.com, blewang1982@163.com, 2271191733@qq.com
}

\begin{abstract}
Keywords: Postgraduate Students; Doctoral and Master Students; Universities and Institutions; Discipline Distribution
\end{abstract}

\begin{abstract}
Graduate education is an important part of higher education; it plays an important role in promoting national innovation capability and economic development. This paper uses the data from China Statistical Yearbook to analyze the development of number of postgraduate students on campus in China, analyze the growth of the total number of postgraduate students on campus, compare the number of doctoral and master students, and the number of students from universities and institutions, at last, analyze the distribution of postgraduate students in different disciplines. The result shows that, from 1952 to 2015, the number of postgraduate students on campus in China has increased from 2763 to 1911406 . From 2005 to 2015, the number of doctoral students on campus increased by $70.76 \%$, the number of master students on campus increased by $101.29 \%$; the proportion of doctoral students on campus is less than $20 \%$, and the proportion of master students on campus is over than $80 \%$. In 2015, the proportion of academic degree students is $64.79 \%$, and the proportion of professional degree students is $35.21 \%$. The proportion of postgraduate students on campus from universities is over than $95 \%$, and the proportion of postgraduate students on campus from institutions is less than 5\%. In the 12 disciplines, education is growing fastest in the last 10 years, and engineering has the largest proportion in 2015.
\end{abstract}

\section{Introduction}

Graduate education is an important part of higher education; it plays an important role in promoting national innovation capability and economic development. ${ }^{[1-8]}$ With the development of higher education in China, the number of postgraduate students in China has been increasing.

There are three main indicators that can be used to describing the number of postgraduate students, including number of enrollment, number of postgraduate students on campus and number of graduate students. Among them, the number of postgraduate students on campus is the most representative indicator. ${ }^{[9]}$

This paper uses the data from China Statistical Yearbook ${ }^{[10]}$ to analyze the development of number of postgraduate students on campus in China, analyze the growth of the total number of postgraduate students on campus, compare the number of doctoral and master students, and the number of students from universities and institutions, at last, analyze the distribution of postgraduate students on campus in different disciplines.

\section{Total Number of Postgraduate Students on Campus}

In 1952, there are only 2763 postgraduate students on campus in China. In 1962, it grew to 6130. In 1965, it dropped to 4546. From 1966 to 1977, there is no statistical data. In 1978, it was 10934, breaking through 10 thousand. In 1986, it was 110371, breaking through 100 thousand. In 2006, it was 1104653, for the first time exceeded one million. From 2000 to 2010, the number increased very fast (refer with: Fig. 1), the linear regression function is $y=112455 x+237261, R^{2}=0.9859$. 


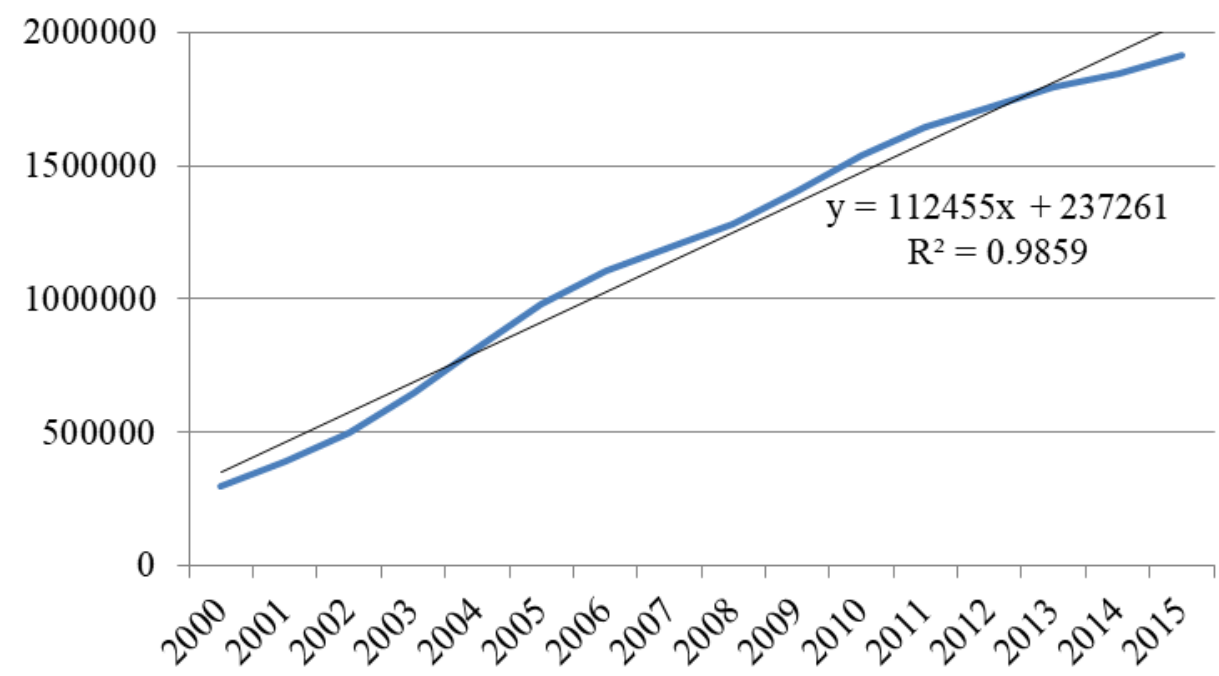

Figure 1. The number of postgraduate students on campus (2000-2015)

\section{The Number of Doctoral and Master Students on Campus}

The number and percentage of doctoral and master students on campus are listed in Table 1. From 2000 to 2015, the number of doctoral students on campus in China has increased from 191317 to 326687, increased by $70.76 \%$; the number of master students on campus in China has increased from 787293 to 1584719 , increased by $101.29 \%$. The proportion of doctoral students on campus is less than $20 \%$, and the proportion of master students on campus is over than $80 \%$ (refer with: Fig. 2).

Table 1 The number of doctoral and master students

\begin{tabular}{|c|c|c|c|c|c|}
\hline Category & Degree & 2005 & 2010 & 2015 & Changed in 10 years \\
\hline \multirow{3}{*}{ Number } & Doctoral & 191317 & 258950 & 326687 & $+70.76 \%$ \\
\cline { 2 - 6 } & Master & 787293 & 1279466 & 1584719 & $+101.29 \%$ \\
\cline { 2 - 6 } & Total & 978610 & 1538416 & 1911406 & $+95.32 \%$ \\
\hline \multirow{2}{*}{ Percentage } & Doctoral & 19.55 & 16.83 & 17.09 & $-2.46 \%$ \\
\cline { 2 - 6 } & Master & 80.45 & 83.17 & 82.91 & $+2.46 \%$ \\
\hline
\end{tabular}

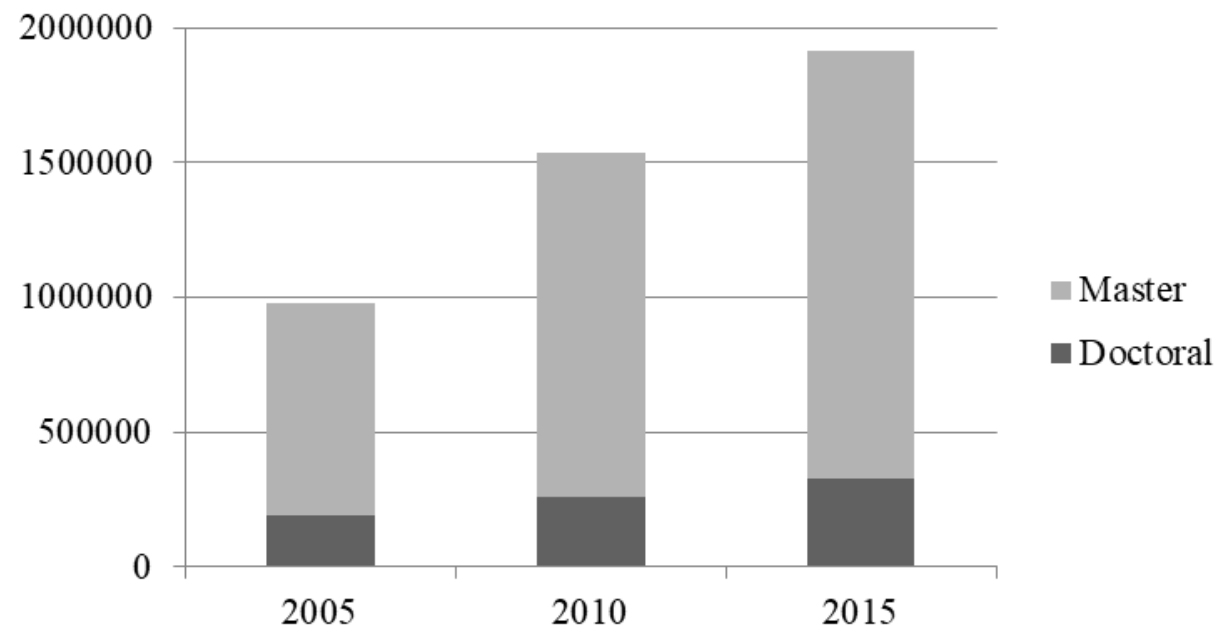

Figure 2. The total number of doctoral and master students 


\section{Two Types of Postgraduate Students on Campus}

In China, postgraduate students are also separated by two types, academic degree and professional degree. In 2015, the contingency table of degree and type is listed in Table 2 and 3.

Table 2 Contingency table displaying degree and type for postgraduate students of China in 2015

\begin{tabular}{|c|c|c|c|}
\hline & Doctoral Degree & Master Degree & Total \\
\hline Academic Degree & 319142 & 919264 & 1238406 \\
\hline Professional Degree & 7545 & 665455 & 673000 \\
\hline Total & 326687 & 1584719 & 1911406 \\
\hline
\end{tabular}

Table 3 Contingency table displaying degree and type based on percentage of overall total (\%)

\begin{tabular}{|c|c|c|c|}
\hline & Doctoral Degree & Master Degree & Total \\
\hline Academic Degree & 16.70 & 48.09 & 64.79 \\
\hline Professional Degree & 0.39 & 34.81 & 35.21 \\
\hline Total & 17.09 & 82.91 & 100.00 \\
\hline
\end{tabular}

\section{The Number of Postgraduate Students on Campus from Universities and Institutions}

In China, only the universities and institutions can train postgraduate students. The number and percentage of postgraduate students on campus from universities and institutions are listed in Table 4. From 2000 to 2015, the number of postgraduate students on campus from universities has increased from 932711 to 1885789 , increased by $102.18 \%$; the number of postgraduate students on campus from institutions has decreased from 45899 to 25617 , decreased by $44.19 \%$.

The proportion of postgraduate students on campus from universities is over than $95 \%$, and the proportion of postgraduate students on campus from institutions is less than 5\%, in 2015, is was only $1.34 \%$ (refer with: Fig. 3).

Table 4 The number of postgraduate students on campus from universities and institutions

\begin{tabular}{|c|c|c|c|c|c|}
\hline Category & Come From & 2005 & 2010 & 2015 & Changed in 10 years \\
\hline \multirow{3}{*}{ Number } & Universities & 932711 & 1482680 & 1885789 & $+102.18 \%$ \\
\cline { 2 - 6 } & Institutions & 45899 & 55736 & 25617 & $-44.19 \%$ \\
\cline { 2 - 6 } & Total & 978610 & 1538416 & 1911406 & $+95.32 \%$ \\
\hline \multirow{2}{*}{ Percentage } & Universities & 95.31 & 96.38 & 98.66 & $+3.35 \%$ \\
\cline { 2 - 6 } & Institutions & 4.69 & 3.62 & 1.34 & $-3.35 \%$ \\
\hline
\end{tabular}

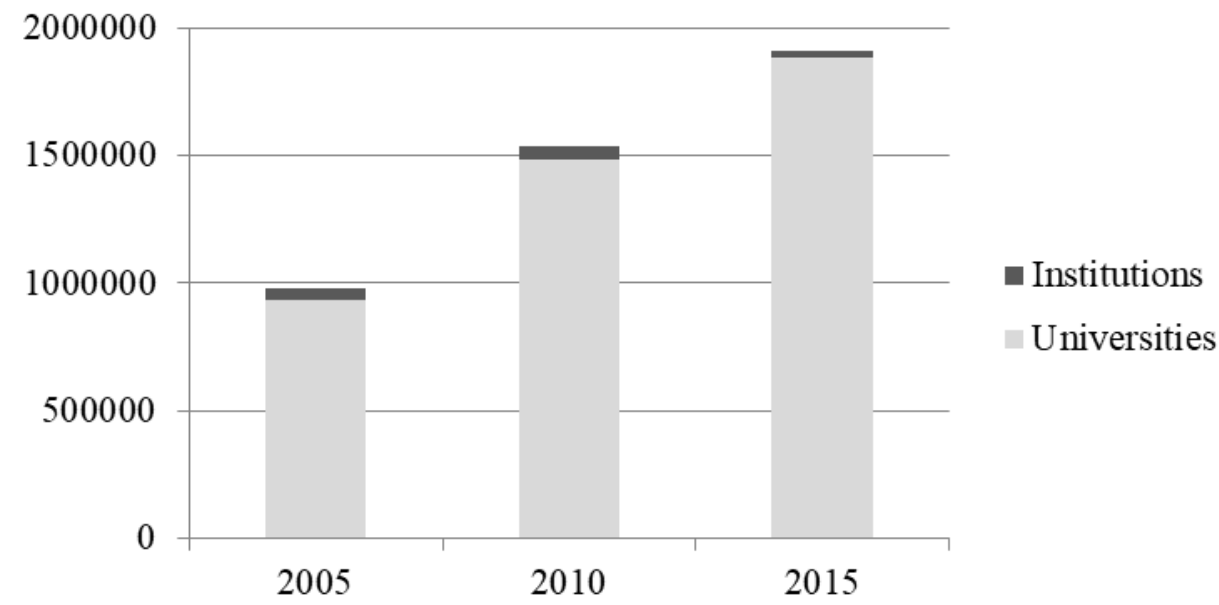

Figure 3. The number of postgraduate students on campus from universities and institutions 


\section{Discipline Distribution of Postgraduate Students on Campus}

Based on the academic field, the discipline in China is separated into 12 area, including philosophy, economics, law, education, literature, history, science, engineering, agronomy, medicine, military and management. The discipline distribution of postgraduate students on campus in China is listed in Table 5 (in 2015 refer with: Fig. 4).

Table 5 The discipline distribution of postgraduate students on campus in China

\begin{tabular}{|c|c|c|c|}
\hline Discipline & 2005 & 2015 & Changed in 10 years \\
\hline Philosophy & 11632 & 14323 & $+23.13 \%$ \\
\hline Economics & 49752 & 81127 & $+63.06 \%$ \\
\hline Law & 65272 & 125335 & $+92.02 \%$ \\
\hline Education & 29855 & 92249 & $+208.99 \%$ \\
\hline Literature & 73000 & 152255 & $+108.57 \%$ \\
\hline History & 13790 & 18610 & $+34.95 \%$ \\
\hline Science & 120510 & 196859 & $+63.35 \%$ \\
\hline Engineering & 369738 & 689597 & $+86.51 \%$ \\
\hline Agronomy & 36061 & 68212 & $+89.16 \%$ \\
\hline Medicine & 100343 & 215232 & $+114.50 \%$ \\
\hline Military & 546 & 688 & $+26.01 \%$ \\
\hline Management & 108111 & 256919 & $+137.64 \%$ \\
\hline Total & 978610 & 1911406 & $+95.32 \%$ \\
\hline
\end{tabular}

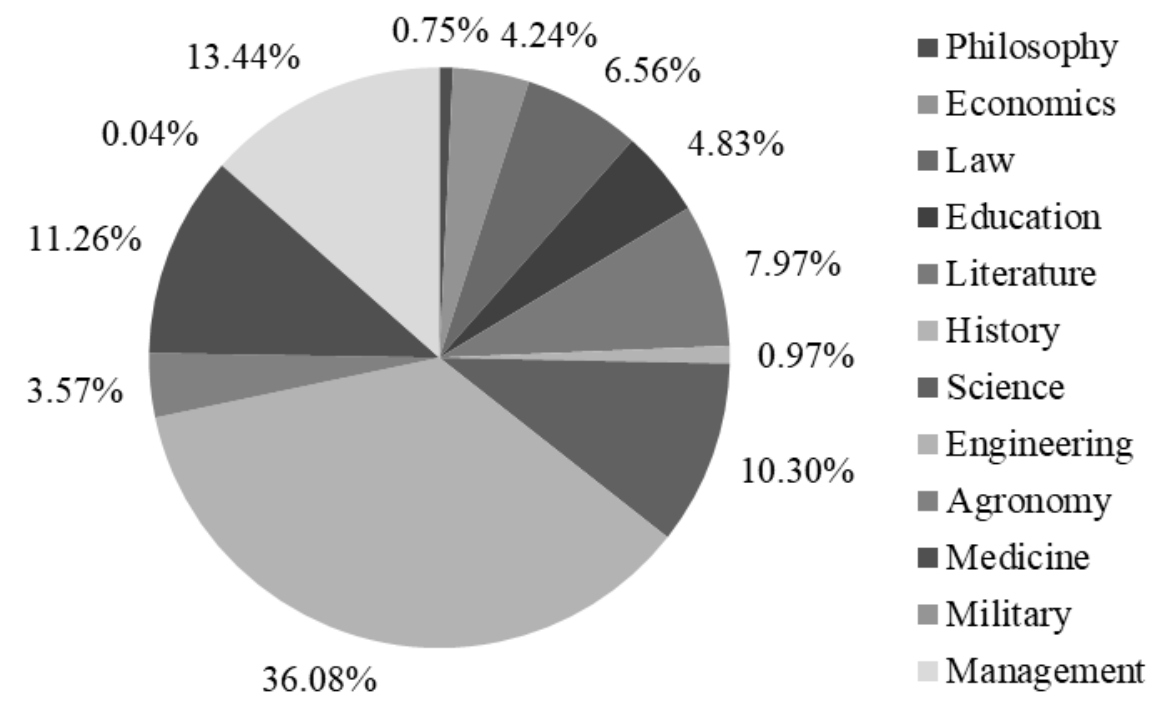

Figure 4. The discipline distribution of postgraduate students on campus in China in 2015

\section{Summary}

This paper uses the data from China Statistical Yearbook ${ }^{[10]}$ to analyze the development of number of postgraduate students on campus in China, analyze the growth of the total number of postgraduate students on campus, compare the number of doctoral and master students, and the number of students from universities and institutions, at last, analyze the distribution of postgraduate students on campus in different disciplines.

The result shows that, from 1952 to 2015 , the number of postgraduate students on campus in China has increased from 2763 to 1911406 . From 2005 to 2015, the number of doctoral students on campus increased by $70.76 \%$, the number of master students on campus increased by $101.29 \%$; the proportion of doctoral students on campus is less than $20 \%$, and the proportion of master students on campus is over than $80 \%$. In 2015 , the proportion of academic degree students is $64.79 \%$, and the proportion of 
professional degree students is $35.21 \%$. The proportion of postgraduate students on campus from universities is over than $95 \%$, and the proportion of postgraduate students on campus from institutions is less than 5\%. In the 12 disciplines, education is growing fastest in the last 10 years, and engineering has the largest proportion in 2015.

\section{Acknowledgements}

This research was supported by the University Basic Scientific Research Foundation of Department of Education of Liaoning Province "Research on the mechanism and countermeasures of enhancing teachers' sense of responsibility and improving teachers' professional ability (WY2016007)”.

\section{References}

[1] H.S. Becker: American Sociologist, Vol.18 (1987) No.1, p.42-45.

[2] N. Liu, L. Liu: Higher Education in Europe, Vol.30 (2005) No.1, p.217-227.

[3] C. Arrigoni, R. Caruso, F. Campanella: G Ital Med Lav Ergon, Vol.37 (2015) No.1, p.39-45.

[4] S. Collins, N. Arthur, C. Brown, B Kennedy: Training \& Education in Professional Psychology, Vol.9 (2015) No.2, p. 153-160.

[5] A. Leshner: Science, Vol.349 (2015) No.6246, p.349.

[6] L. Hakkola, J. King: Innovative Higher Education, Vol.41(2016) No.2, p. 137-152.

[7] K. Shih: European Spine Journal, Vol.9 (2016) No.3, p.213-217.

[8] L. Neuhauser, C. Pohl: Springer International Publishing, Vol.116 (2015) No.7, p.2931-2938.

[9] G. Sherwood, H Liu: Nursing Outlook, Vol.53 (2005) No.1, p.15-20.

[10] Information on http://www.stats.gov.cn/. 